\title{
Retratos da violência numa perspectiva comparada entre Memórias do cárcere, de Graciliano Ramos e $A$ vida verdadeira de Domingos Xavier, de José Luandino Vieira
}

Débora Leite David ${ }^{1}$

RESUMO: Este artigo apresenta alguns aspectos da violência que encontramos nas obras Memórias do cárcere, de Graciliano Ramos e A vida verdadeira de Domingos Xavier, de José Luandino Vieira. A violência como mecanismo poderoso de coerção e reificação dos indivíduos, perpetua-se na linha do tempo através da literatura ao impregnar o imaginário coletivo das conseqüências do seu impacto.

ABSTRACT: This article presents a few aspects of the violence which is found in the novels Memórias do cárcere, by Graciliano Ramos and A vida verdadeira de Domingos Xavier, by José Luandino Vieira. The violence like a powerful mechanism of coercion and reification to the individuals, perpetuates itself at the time line through literature, impregnating the collective imaginary of consequences from its impact.

PALAVRAS-CHAVE: Violência; Graciliano Ramos; José Luandino Vieira; Reificação.

KEYWORDS: Violence; Graciliano Ramos; José Luandino Vieira; Reification.

A violência ${ }^{2}$, especialmente a tortura, se evidencia como um mecanismo poderoso para a desumanização de indivíduos inseridos em experiências de regimes autoritários. Percebemos que a violência propaga seus efeitos além da imposição de determinadas forças sociais e políticas, perpetuando-se na linha do tempo ao impregnar o imaginário individual e coletivo das conseqüências do seu impacto. No acompanhamento da trajetória das personagens centrais de Memórias do cárcere - livro de memórias do escritor brasileiro Graciliano Ramos que retrata o período da ditadura de Getúlio Vargas no final da década

\footnotetext{
${ }^{1}$ Doutoranda em Estudos Comparados de Literaturas de Língua Portuguesa, FFLCHUSP. Bolsista do CNPQ. Pesquisa: O desencanto utópico ou o juízo final: um estudo comparado entre A costa dos murmúrios, de Lídia Jorge e Ventos do apocalipse, de Paulina Chiziane. E-mail: dleitedavid@uol.com.br

${ }^{2}$ Adotamos a acepção tomada por Y. Michaud e H. Arendt para contemplar a violência em seus vários aspectos.
} 
de 1930 - e de A vida verdadeira de Domingos Xavier - romance do escritor angolano José Luandino Vieira ambientado em Angola no período imediatamente anterior à luta armada (1961) — quando aquele país ainda se encontrava sob a égide do sistema colonial de Portugal buscaremos refletir acerca dos efeitos da violência sobre a forma de representação da experiência do indivíduo ou da coletividade subjugada.

As obras escolhidas para esta breve análise compuseram o corpus de nossa pesquisa de mestrado, que foi desenvolvida no sentido de evidenciar a importância da literatura e o papel do escritor em situações de autoritarismo e violência, com ênfase na situação dos direitos humanos no contexto de cada uma das sociedades representadas na ficção. Apesar de estarmos diante de obras compostas em gêneros literários diversos (romance e memórias) e de efabulações tematizadas em lugar e momento histórico diferentes (Brasil dos anos 30 e Angola dos anos 60), existe um elo de conexão que motiva o seu estudo comparado, desenvolvido pelas observações teóricas do macrosistema de literaturas de língua portuguesa que Benjamin Abdala Júnior ${ }^{3}$ propõe a partir da noção de sistemas literários nacionais de Antonio Candido. O macrossistema permite a visualização de um campo comum aos sistemas literários nacionais de língua portuguesa, onde muito mais do que compartilhar da mesma língua como instrumento de comunicação e expressão, abrange formas, modelos e temas que ultrapassam as fronteiras de seus países de origem, propiciando o alicerce necessário para este estudo comparativo.

Dos fios de sua memória Graciliano tece uma narrativa a partir da sua prisão em março de 1936, e da qual surge um relato, um testemunho dos bastidores carcerários na ditadura de Getúlio Vargas (1930-1945). Graciliano, este narrador-personagem ${ }^{4}$, ente fragmentado, é um narrador perplexo que para além de descrever os comportamentos

\footnotetext{
3 ABDALA JÚNIOR, Benjamin. De vôos e ilhas: literatura e comunitarismos. S. Paulo: Ateliê 2003, p. 103.

${ }^{4}$ BASTOS, Hermenegildo. Memórias do cárcere. Brasília: Editora UnB, 1998, p. 117.
} 
que desfilam a sua frente, questiona-os, contempla-os com o benefício da dúvida, e parece demonstrar uma precariedade ao proferir julgamentos sobre o que acontece à sua volta. Percebemos que a personagem sempre tem um pronto julgamento que é proferido segundo valores morais sólidos, para logo a seguir o narrador lançar um olhar crítico distanciado pelo tempo, liberto das amarras de preconceitos e de valorações precipitadas suscitadas pelo calor da hora, e assim compreender atitudes e situações próprias da cadeia.

A narrativa segue mostrando uma escala crescente de violência e desumanização do indivíduo seja através do silêncio das autoridades que em momento algum justificam seus atos, seja através das transferências aleatórias e sem sentido, da redução do acesso às condições mínimas de higiene, acomodação e alimentação, entre outras estratégias de aniquilamento do sujeito.

Neste passo, parece que o narrador usa o recurso de jamais nomear os perpetrantes dos atos de violência e aniquilação forçada, em resposta à sua própria desumanização, pois lhe são subtraídos quase todos os seus hábitos de civilidade e dignidade. Os algozes nunca recebem nome, são seres relegados ao anonimato, por certo como punição, por não merecerem qualquer reconhecimento de urbanidade, visto que se comportam como animais tomados pela ira bestial. Poucos se redimem e alcançam a sua identificação humana como acontece em Memórias do cárcere com o soldado cafuzo que se torna Alfeu. Enquanto sacudia violentamente o "primeiro sujeito da fila vizinha" na formatura geral, o soldado é denominado apenas por "cafuzo", sendo o protagonista de uma agressão desmedida e sem razão aparente. No entanto, ao se postar diante do narrador, o soldado sem jeito e com palavras sem nexo a pedir a redação de um discurso, recebe um nome, é elevado à condição humana. Assim como os algozes impõem a desumanização das suas vítimas, das criaturas sob a sua custódia, o narrador parece lhes impor esta pena, nenhuma identificação civilizada além da denominação da sua bestialidade, o que parece indicar entre outras possíveis leituras a tentativa de desautorizar o discurso do outro. 
Um dos primeiros indícios que encontramos a respeito desta estratégia utilizada em suprimir o nome de determinadas personagens em Memórias do cárcere está no prefácio à obra escrito por Nelson Werneck Sodré. No trecho que transcrevemos abaixo, o autor do prefácio discorre sobre as qualidades da narrativa em razão da sensatez do escritor no cuidado com os excessos da retórica e da adjetivação:

Havia asperezas - contá-las com arte, permitiu reconstituí-las sem muito adjetivo, sem abuso da retórica, sem desmandos, sem descomedimentos. Raro o qualificativo que se pega à criatura como um esparadrapo fica a marcá-la. Do idiota que pretendia fuzilá-lo, conforme conta no primeiro volume, lá longe, no segundo, aparece o adjetivo "grotesco", e mais nada. E que era aquele sub-homem senão isto, grotesco? Adjetivá-lo de outra forma, denunciar-lhe a maldade, a ignorância e estupidez, seria demasiado.

Ao falar como falou ao romancista preso estava sendo precisamente grotesco e nada mais do que isso. $\mathrm{O}$ adjetivo não tem substituto. Não havia razão para afirmá-lo dono de outras deficiências. Demais, nem o seu nome aparece. O que foi um traço de inteligência, retirando ao imbecil a única oportunidade de entrar para a eternidade. Para que guardar-lhe o nome? Representava apenas um símbolo e como símbolo era grotesco. Nada mais do que isso, que já foi excessivo. ${ }^{5}$

Este aspecto da ausência de nomeação, da recusa na atribuição de nome próprio às personagens que possuem destaque nos atos de violência, opressão ou dominação dentro da narrativa, parece mostrar a intenção de exclusão, do apagamento do indivíduo que está sendo colocado à sombra, e assim a imposição do silenciamento de sua voz. Corrobora esta impressão a colocação feita por Lévi-Strauss ${ }^{6}$, em que o nome próprio é formado pela destotalização da espécie e pelo levantamento de um aspecto parcial. Deste modo, o nome próprio caracteriza-se por ser uma marca de individualização ao identificar o sujeito que é nomeado. Além desse aspecto, o nome próprio indica, outrossim, o pertencimento do sujeito a uma classe predeterminada (família, classe social, clã, meio cultural, nacionalidade, etc.), ou seja, a

${ }^{5}$ SODRÉ, Nelson Werneck. Prefácio. In: RAMOS, Graciliano. Memórias do cárcere. $19^{a}$ ed. Rio, S.Paulo: Record, 1984, vol. 1, p. 16-17.

${ }^{6}$ LÉVI-STRAUSS, Claude. La pensée sauvage. Ed. Plon, Paris, 1962, p. 236. 
sua inclusão em um grupo específico. Por isso, "o nome próprio é a marca lingüística pela qual o grupo toma posse do indivíduo7", e a falta desta marca importa em exclusão, em banimento, destacando a autoridade e poder do grupo. Também encontramos referência desta individualização em vários teóricos literários, como em Wellek e Warren $^{8}$, ao definirem o nome próprio das personagens como a primeira fase de sua formação, porque a nomeação da personagem é que lhe dá vida muitas vezes antes mesmo da sua caracterização psicológica.

A vida verdadeira de Domingos Xavier é um romance que tematiza o período imediatamente anterior à irrupção da luta armada em Angola (1961), e se traduz numa narrativa bruxuleante no tempo, indo e vindo pela cronologia dos acontecimentos conforme o narrador se desloca entre os grupos de personagens que distinguimos ao longo do texto. A partir do eixo principal do enredo - a prisão do operário negro Domingos Xavier - encontramos num primeiro plano a situação social e política em Luanda que é de intensa repressão em razão da recente instalação da polícia política portuguesa, à época denominada por PIDE - Polícia Internacional de Defesa do Estado. A PIDE tinha entre outras finalidades a função de enfraquecer e extinguir o movimento de libertação colonial organizado por um grupo heterogêneo composto por brancos, mestiços e negros, segmento formado por angolanos, em razão da crescente consolidação de um sentimento nacionalista fomentado pela elite e pela intelectualidade luandense.

Em segundo plano percebemos o desenrolar cotidiano da vida dos moradores dos musseques ${ }^{9}$ de Luanda, com a participação, ainda que pequena, mas nem por isso menos importante, de figuras como a da criança e do velho, representadas respectivamente pelo menino Zito e

\footnotetext{
7 MACHADO, Ana Maria. Recado do Nome. São Paulo: Martins Fontes, 1991, p. 5.

8 Wellek et Warren. La théorie littéraire. Paris: Seuil, 1971.

9 Musseque é a designação que o povo deu aos bairros pobres que se formaram à volta de Luanda, originalmente em razão da areia avermelhada do terreno. Estes bairros periféricos representaram um novo espaço social extremamente fértil para o entrecruzamento de culturas, em que se encontravam os pequenos agricultores vindos de várias partes do interior de Angola - oriundos de diversas etnias - e os imigrantes portugueses de baixa renda.
} 
pelo velho Petelo, nos assuntos do movimento de libertação e a solidariedade entre os pares para o enfrentamento das dificuldades impostas pelo sistema colonial português como a miséria e o racismo, e a intensa perseguição política.

Temos aqui também a bestialidade do algoz, a fúria a conduzir o episódio da violência física no seu mais alto grau, culminando na morte da vítima. A personagem Domingos tem consciência desde a sua prisão de que será compelido a confessar os nomes daqueles que estão envolvidos com os "assuntos angolanos", e desde o princípio toma uma postura heróica mantendo-se fiel aos seus companheiros ao suportar os açoites de "cavalmarinho"10, os pontapés e o ardume do jindungo"11 em suas feridas. Apesar de desejar retornar à sua família e ter a sua vida de volta, a personagem Domingos demonstra reconhecer a importância do seu silêncio naquela situação de prisão e tortura, pois além de preservar as informações e fortalecer o grupo, Domingos está dando um valioso passo em direção ao fim do sofrimento da sua gente, submetida à exploração e aniquilação imposta pelo sistema colonial português.

Assim como em Memórias do cárcere, percebemos neste romance de Luandino a ausência da nomeação do algoz, do agente dos atos de violência durante os interrogatórios, sendo designado apenas como o “cipaio", o "agente", o "chefe". Por ocasião da prisão de Domingos na Administração - localizada na vila próxima à barragem — os cipaios são referidos como executores da tortura sem um maior detalhamento. Numa etapa posterior da narrativa a situação se reverte e eles são nomeados em contexto de desaprovação por parte de Maria e Domingos, como aqueles que pertencem ao seu povo e que vivem na mesma comunidade, Toneto, João e Mandombe. Quando Domingos é transferido para o Posto dos musseques em Luanda, temos o chefe de brigada, português, que não recebe nome, apenas patente, o cipaio que é chamado por "Vinte-Sete" pelo chefe, e o agente de polícia, Pereira da Cunha. Vale notar que, nesse espaço, o cipaio é um ajudante para

10 Cavalo-marinho: chicote feito de couro de hipopótamo.

${ }^{11}$ Espécie de pimenta usada como condimento. 
pequenos serviços. O carcereiro que toma conta das chaves é branco e o interrogatório realizado mediante tortura é conduzido pelo agente, também branco. Porém, o procedimento é conduzido principalmente pelo próprio chefe de brigada, responsável como superior hierárquico e executor dos golpes fatais desferidos contra Domingos.

Voltando à apreciação da natureza da violência podemos dizer que esta se apresenta em diferentes formas e não podemos simplesmente pinçar uma definição única, pois existem diversas leituras em razão da sua contextualização. Segundo Yves Michaud, uma conceituação possível na tentativa de sanar este problema seria de que "há violência quando, numa situação de interação, um ou vários atores agem de maneira direta ou indireta, maciça ou esparsa, causando danos a uma ou várias pessoas em graus variáveis, seja em sua integridade física, seja em sua integridade moral, em suas posses, ou em suas participações simbólicas e culturais"12. Desta forma seria possível dar conta das várias faces que compõem a violência. Uma delas, a interação da máquina administrativa que dilui responsabilidades ao multiplicar os participantes; o modo de sua produção, que com o avanço tecnológico está cada vez mais indireto e "limpo"; ou ainda, a sua distribuição, que pode ser maciça ou gradual. Temos também que ressaltar que a violência é capaz de provocar os mais diferentes tipos de danos de ordem física, psíquica, moral, patrimonial e até mesmo cultural.

Essa dificuldade de definição da violência é atribuída ao elemento de imprevisibilidade total que se encontra na execução ou implementação da mesma, costumeiramente marcada pela ausência de forma e regramento. No caso em tela, qual seja a situação de repressão política e violência descrita nas obras estudadas, visualizamos uma categoria de violência que é imposta pelo próprio Estado para manter o poder político, afirmando a sua supremacia, ainda que tenha de ignorar as limitações legais que regem a instituição do poder. Neste ponto

12 MICHAUD, Yves. A violência. São Paulo: Editora Ática, 2001, p. 10. 
percebemos a instauração de um paradoxo, uma vez que o Estado precisa das limitações legais para ser reconhecido como Estado soberano e não sofrer represálias por seus pares no cenário internacional, Todavia, o Estado necessita neutralizar ou controlar toda e qualquer instituição que ameace a centralização dos três poderes apenas no âmbito do Executivo. Deparamo-nos com o "Estado fora-dalei”, ${ }^{13}$ para usar uma expressão de Walnice Nogueira Galvão, que através de artifícios "pseudo-legais" como estado de sítio, estado de emergência, tribunais de exceção, lei marcial, etc. transforma a vida política em prática clandestina, com a conseqüente modificação de estatuto do cidadão cumpridor da lei e da ordem, que vivencia a inversão dos papéis, passando de mocinho a bandido.

Michaud ressalta a surpreendente generalização da tortura no século XX que se reveste de nova roupagem através do terror imposto pelo Estado, colocando os cidadãos sob a ameaça do risco de tortura se forem presos. Interessante notar a mudança que houve quanto à natureza da tortura desde o século XVIII. Como podemos ver a partir de Beccaria, ${ }^{14}$ a tortura naquele tempo tinha a específica e isolada finalidade de obter a confissão. Durante o século XX encontramos a tortura como um instrumento que ainda é utilizado em interrogatórios para promover a confissão do acusado. Contudo, notamos que a sua natureza foi ampliada no sentido de imprimir à sua vítima a humilhação e a noção de precariedade da vida, não existindo necessariamente o objetivo da confissão.

Em Memórias do cárcere temos a violência que surge para sustentar o poder. Percebemos além do emprego da força física, a violência como intimidação moral que se realiza com a inobservância da ética e da lei, um excesso incentivado pelo Estado, com as prisões arbitrárias, mas também a crueldade nos relacionamentos interpessoais, em que, por exemplo, o soldado carcereiro impõe a

13 Expressão utilizada por Walnice Nogueira Galvão em palestra "Os fora-da-lei da literatura”, proferida no dia 05 de junho de 2004 no Centro Cultural Banco do Brasil (São Paulo), durante o evento "Novos olhares sobre a Literatura".

${ }^{14}$ Cf. BECCARIA, Cesare. Dos Delitos e das penas. São Paulo: Martin Claret, 2000. 
disciplina aos presos com a humilhação (braços cruzados) e a aniquilação (surras, fome, trabalho forçado). Como salienta Alfredo Bosi, a "violência ou solidariedade podem irromper de modo aleatório, a qualquer momento, no anonimato do cárcere. O que oprime o sujeito, aqui tornado objeto, é não saber de quem virão, nem quando, nem como, nem por quê". ${ }^{15}$

No romance angolano, a personagem Domingos demonstra uma alegria incontida em morrer sem delatar seus companheiros. A morte é um bálsamo que significa muito mais do que o término do suplício físico: é uma afirmação da força e da vitalidade do movimento de libertação que continua mais forte depois da sua morte como percebemos pela aclamação feita pela personagem Mussunda no capítulo final do romance. Neste caso temos um exemplo do fenômeno da fraternidade no campo de batalha descrito por Frantz Fanon, em que a violência coletiva engendra uma cumplicidade trazendo a morte individual como elemento vitalizador da imortalidade do grupo, mesmo que contraditório visto que a morte é a experiência mais antipolítica que existe.

Ambos os escritores retratam a violência através de uma narrativa marcada por movimentos temporais em que o narrador se desloca do presente ao passado. Enquanto no romance de Luandino vemos inúmeras analepses, em seu livro de memórias, Graciliano apresenta um narrador que constantemente menciona fatos do presente do seu narrar, quando se afasta da continuidade da narração para dizer sobre algo que lhe inquieta no momento presente da escrita. Esta característica das narrativas estudadas parece demonstrar uma dificuldade na superação dos acontecimentos violentos que permeiam cada uma das obras. A par dessa diferenciada narração, percebemos em ambas as personagens centrais a perda da noção de duração temporal dos episódios de violência a que ficam submetidas.

15 BOSI, Alfredo. "A escrita do testemunho em Memórias do cárcere". In: id. Literatura e resistência. São Paulo: Companhia das Letras, 2003, p. 231. 
A princípio, podemos achar que a repetição de episódios traumáticos através da ficção demonstre a não superação do trauma, todavia, a escrita pode significar justamente a saída para o afastamento da desumanização imposta pelo efeito causado pela violência. Afinal, parece que é por meio da tensão entre a linguagem e a violência que o escritor poderá buscar a superação do trauma, ao criar uma forma de resistência ao silêncio e a morte. Os escritores em questão - Graciliano e Luandino - parecem ter cumprido o seu destino, como intelectuais, qual seja, de enunciar a história dos conflitos de sua sociedade.

No caso de Luandino Vieira, conhecido não só por sua brilhante produção literária, mas também por seu envolvimento na mobilização política contra a dominação colonial através do MPLA ${ }^{16}$, podemos perceber que, se por um lado, sua atuação foi alentadora para os companheiros de militância ao narrar sobre as prisões, as torturas e a luta clandestina, por outro, pôde envolver as massas populares na consciência do seu modo de ser ao imprimir à sua narrativa dos fatos da vida cotidiana nos musseques a forma da oralidade tradicional africana. Graciliano Ramos, por sua vez, teve a vida do sertanejo como instigação que perpassa quase toda a sua obra, buscando retratar em sua narrativa a realidade do seu lugar, um nordeste miserável e mantido sob o jugo do coronelismo. E o seu discurso narrativo carregado de intensa crítica à realidade, transformou-se em pesadelo culminando com a sua prisão, a qual será retratada na forma de memórias para denunciar os porões do "fascismo tupinambá17".

Para refletirmos quanto aos efeitos da violência sobre a forma de representação literária da experiência do indivíduo ou da coletividade subjugada, apontamos algumas pistas que indicam uma certa instabilidade na construção das efabulações nas obras citadas. Temos inicialmente que voltar-nos para o caso do narrador fragmentado que

\footnotetext{
16 Movimento Popular de Libertação de Angola que surgiu pela mobilização de jovens intelectuais mestiços, brancos e negros na década de 1950, com atividades panfletárias e culturais que incitavam a mobilização do povo e reivindicavam a independência do país.

17 Expressão utilizada por Graciliano Ramos para denominar a ditadura de Getúlio Vargas.
} 
surge em Memórias do cárcere como uma mescla entre autor, narrador e personagem, e traz o leitor a um "presente" comum quando realiza intervenções como referências ao presente da escrita ou caminhos para a leitura. Em A vida verdadeira de Domingos Xavier, o narrador movimenta-se entre a terceira e a primeira pessoa, colando-se a alguma das personagens para expressar divagações e pensamentos. Outra pista seria a ruptura com a continuidade temporal que, a nosso ver, pode ter sido causada pelo impacto traumático da violência e de perdas vividas. Essa descontinuidade pode ser verificada também na voz narrativa, que se interroga e se desloca. Ambos os casos possuem a ruptura com a continuidade temporal.

A violência, mais do que simplesmente descrita, impregna de modo indelével o foco narrativo, atingindo assim um grau diferenciado na sua representação. Entendemos que ao tratar a violência como matéria para a sua criação literária, Luandino e Graciliano imprimem ao seu texto um caráter ético e moral para desautorizar uma eventual legitimidade dessa violência. Esta reflexão nos leva ao encontro da colocação de Roberto Schwarz pela qual "a fratura da forma aponta para impasses históricos," 18 e corrobora a perspectiva em que a ruptura aponta para a existência de tensões que permeiam a obra ficcional, indicando um contexto sócio-político problemático enfrentado pelo escritor em dado momento.

\section{Referências bibliográficas}

ABDALA JÚNIOR, Benjamin. De vôos e ilhas: literatura e comunitarismos. São Paulo: Ateliê Editorial, 2003.

ARENDT, Hannah. Crises da República. 2 ${ }^{\text {a }}$ ed. São Paulo: Editora Perspectiva, 1999.

BASTOS, Hermenegildo. Memórias do cárcere. Brasília: Editora UnB, 1998.

BOSI, Alfredo. Literatura e resistência. São Paulo: Cia. das Letras, 2002.

FANON, Frantz. Os condenados da terra. $2^{\mathrm{a}}$ ed. Rio de Janeiro: Civilização Brasileira, 1961.

18 SCHWARZ, Roberto. "Questões de forma". In: id. Um mestre na periferia do capitalismo. São Paulo: Duas Cidades, Ed. 34, 2000, p. 182. 
GINZBURG, J. Literatura brasileira: autoritarismo, violência, melancolia. In Revista de Letras, São Paulo: 43 (1): 57-70, jan-jun 2003.

LÉVI-STRAUSS, Claude. La pensée sauvage. Paris: Ed. Plon, 1962.

MACHADO, Ana Maria. Recado do Nome. São Paulo: Martins Fontes, 1991.

MICHAUD, Yves. A violência. São Paulo: Editora Ática, 2001.

MARCO, Valéria De. Questões sobre a literatura de testemunho. In Revista de Língua e Literatura, S. Paulo: 25: 153-167, 1999.

RAMOS, Graciliano. Memórias do cárcere. 19ª ed. Rio/S. Paulo: Record, 1984. 2 vols.

SCHWARZ, Roberto. Ao vencedor as batatas. $5^{\text {a }}$ ed. São Paulo: Editora 34, 2000.

. Um mestre na periferia do capitalismo. $4^{\mathrm{a}}$ ed. São Paulo: Editora 34, 2000.

VIEIRA, J. Luandino. A vida verdadeira de Domingos Xavier. São Paulo: Ática, 1980.

WELLEK et WARREN. La théorie littéraire. Paris: Seuil, 1971. 